\title{
Embodied digital technology and transformation in higher education
}

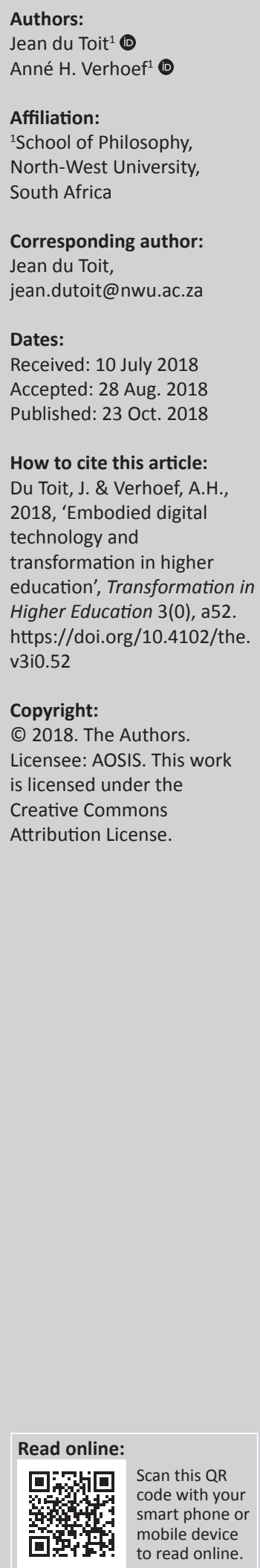

Background: The use of digital technology in higher education is overwhelmingly positively assessed in most recent research literature. While some literature indicates certain challenges in this regard, in general, the emphasis is on an encouragement and promotion of digital technology in higher education. While we recognised the positive potential of the use of digital technology in higher education, we were cautious of an instrumentalist and disembodied understanding of (digital) technology and its potential impact on higher education - as a sector of education and as a body of students.

Aim: To re-conceptualise the way in which technology is understood for its use in the higher education sector, as is argued, would be of benefit for transformation in higher education.

Setting: South African Higher Education sector.

Methods: Phenomenology of embodiment.

Results: An embodied understanding of technology through the embodied phenomenology of Merleau-Ponty and an explication of its potential for transformation in higher education via the working concept of the Embodied Screen leads to a full understanding of the student as embodied and socially-embedded individual.

Conclusion: A more holistic and embodied understanding of digital technology serves to supplement transformation in higher education, especially if transformation is itself understood in concrete social and bodily terms as is the case in the South African context.

\section{Introduction}

In the first part of the article, we present a brief overview of the positive assessment of the use of technology in higher education. The term 'technology', as used throughout this article, refers specifically to digital technology which is encountered in its various forms - Internet, smartphones, computers, etc. - and which is used as such in the higher education context. 'Higher education' refers to 'all learning programmes leading to qualifications higher than the proposed Further Education and Training Certificate or the current Standard ten certificate' (South Africa, Department of Education 1997:11). Our focus will mainly be on the 26 public universities in South Africa, functioning within a highly technologised global context. The first part of the article ends with a critique of technology in higher education. In response to this critique, we argue that a more embodied understanding of technology is needed than the predominantly instrumentalist view of technology.

In the second part of the article, we elucidate this embodied understanding of technology through an appropriation of the philosopher Maurice Merleau-Ponty's embodied phenomenology in the context of digital technology. The working concept of the Embodied Screen is introduced to highlight what this alternative understanding of technology could entail: a foundational recognition of the student's embodiment as means of engaging with technology in higher education. In the last part of the article, we envisage and discuss the implications of an embodied understanding of technology for the transformation of higher education. Technology can play a major role in the transformation of higher education in general, but if transformation is understood in concrete social and bodily terms - as is the case in South Africa - a more holistic and embodied understanding of technology is needed. This point is explicated in the conclusion by highlighting the implications of an embodied understanding of technology for transformation in higher education. 


\section{Technology in higher education}

The use of technology in higher education is not only taken for granted, but is also typically encouraged and promoted. For example, Waghid and Waghid (2016:281) argue that, 'the onus is on both tertiary institutions and the state to enhance (higher) education by cultivating students' capacities to use the Internet and to enhance their digital literacy', because ' $r$ r esearch has shown that the application of digital technology has enhanced teaching and learning' (p. 266). Underwood (2009:8), who has conducted several studies on the impact of digital technology application in education, has a similar view. Wankle (2011:6) also agrees and argues in his book, Teaching Arts and Science with New Social Media, that the use of digital technology (like social media) could potentially stimulate technical literacy, social interaction and critical reflection and, furthermore, serve as a catalyst for cultivating excitement, interaction and sharing in students (p. 7). This positive potential of the use of technology in higher education has found prominence in various educational policies of government and of universities. The South African White Paper on Education, for example, states that 'The Ministry of Education is committed to help harness the new teaching and learning technologies, especially through its technology enhanced learning initiative' (South Africa, Department of Education 1997:7).

The transformative power of digital technology for higher education is similarly widely acknowledged. For example, in the United States the Office of Educational Technology has recently published a supplement to the National Education Technology Plan under the title 'Reimagining the Role of Technology in Higher Education' and states that technology 'offers the opportunity to catalyse more significant reforms to educational structures and practices' (United States, Department of Education 2017:9). The NMC Horizon Report of 2017: Higher Education Edition ${ }^{1}$ points out that technology continues to shape the internationalisation of higher education. Internationalisation can, in turn, 'broaden the discourse on transformation and encourage the rethinking thereof' (Du Preez, Simmonds \& Verhoef 2016:7). In the South African context, Waghid et al. (2016:282) argue that the use of digital technology in higher education can 'better students' lives as digitally literate thinkers, and democratic and deliberative citizens'.

There are, of course, concerns amongst critics about the use of digital technology in higher education and of its positive transformative potential. Such concerns include issues of cost-effectiveness, the relative benefit of digital technologies (Wainer et al. 2008:24), issues of access and equity, digital literacy as an isolated technological skill (Adams Becker et al. 2017:22), technological training of lecturers, integration of technology into curriculums (Georgina \& Olson 2008:1) and the achievement gap ('a disparity in the enrolment and

1 For this report 78 global experts in the field were consulted and it charts the fivevear impact of innovative practices and techno wo year impact of innovative practices and technologies for higher education across the globe. With more than 15 years of research and publications, the NMC Horizon Project can be regarded as education's longest-running exploration of emerging technology trends and uptake. (Adams Becker et al. 2017:2) academic performance between student groups, defined by socioeconomic status, race, ethnicity, or gender' [Adams Becker et al. 2017:22]). Other challenges include increased plagiarism, loss of focus (mindfulness, attention and contemplation) or scattered attention by students, uncertainty of the role of the educator and the challenge for educators to stay organised and current, while 'educational needs, software, and devices advance at a strenuous rate' (Adams Becker et al. 2017:23). Furthermore, there are often assumptions and unrealistic expectations of learning enhancements through technology which are not realised. Kirkwood and Price (2014:26), for example, analysed articles on technology enhanced learning from 2005 to 2010 and conclude that 'there seemed to be many cases of deterministic expectations that introducing technology would, by itself, bring about changes in teaching/learning practices'. However, this is not necessarily the case, as Flavin (2017) indicates that:

Given the ubiquity of technology usage in higher education, there is a need to understand more fully the technology practices of students and lecturers, with a view to rethinking approaches to technology enhanced learning. (p. 3)

Despite some of these concerns about the use of digital technology in higher education, the vast majority of research literature on this matter (as previously mentioned) is positive about its use and potential. Our aim in this article is not to oppose this positive assessment of digital technology, but rather to encourage a critical engagement with questions regarding the understanding and use of technology in higher education. This will be done in order to find a more holistic and embodied understanding of technology in higher education. Our focus will therefore mainly be on the 'intrinsic qualities' of technology, rather than on its practice (although some practical implications will be discussed). Our contention is that technology, as it is used and understood in higher education, is predominantly and in principle based on a naïve instrumentalist understanding of technology. We argue that, taking such an instrumentalist understanding of technology as basis or, in other words, suggesting that technology functions in a manner that pays no heed to the student as embodied being, disregards the foundational character of the bodily existence and embodied needs of its users. Technology, utilised in this way - as a one-size-fits-all approach - in effect ignores students' embodied contexts and personhood. This can have negative consequences for transformation in higher education, wherein transformation entails concrete changes in our society. The Education White Paper clearly states that:

[t]he higher education system must be transformed to redress past inequalities, to serve a new social order, to meet pressing national needs and to respond to new realities and opportunities. (South Africa, Department of Education 1997:2)

Transformation was even more concretely understood in the 2008 Report of the Department of Higher Education - based on the work of the Ministerial Committee on Transformation and Social Cohesion and the Elimination of Discrimination in 
Public Higher Education Institutions (MCTHE) (South Africa, Department of Education 2008). Compare also:

Transformation of higher education includes the following issues: epistemological change; discrimination and exclusions in terms of religion, ethnicity, sexual orientation, class and language; Africanization or decolonisation of the curriculum; beliefs, attitudes, values and commitments of the whole system; power; diversity; and intellectual justice. (Du Preez et al. 2016:3)

Thus, while a more holistic and embodied understanding of technology might address some of the practical problems of the use of digital technology listed above such as the question of access and questions of personhood, its benefit may be significant in terms of transformation in higher education.

In the next section, some examples are given with reference to how technology in higher education is mostly understood as something disembodied and instrumentalist. These examples stand in stark contrast to the views of Clark and Chalmers (1998:7), for example, who argues in their seminal article 'The Extended Mind' that technology is actually part of us. We take this view of Clark and Chalmers even further. Technology is not only 'tools' that can be seamlessly integrated into the thinking process (as Clark and Chalmers argue), but also challenges us and integrates on a much more holistic and embodied manner with who we are. For us to trace such an embodied understanding of technology, we must first seek to understand the disembodied and instrumentalist approaches towards technology that hold sway in contemporary discussions of the use of digital technology in higher education.

\section{A disembodied and instrumentalist view of technology: A challenge and obstacle to transformation in higher education}

An instrumentalist view of technology is typical of and derived from the approaches of pragmatism and social constructivism. Within the broader field of Philosophy of Technology, these approaches have become dominant since the empirical turn from the 1980s onwards (Du Toit 2018:3039). Such approaches cannot adequately and encompassingly describe the engagement between the individual and the technological artefact because of their inability to trace embodiment within this relation (Du Toit 2018:40-46). This is a centrally important point for the use of technology in higher education, because delimiting approaches (such as disembodied and instrumentalist perspectives) reduce the phenomenon of digital technology to a form of social epistemology which, in turn, obscures the true dynamically entangled nature of the individual and the digital technology artefact. The unfortunate result is that the full human (bodily) experience in this process is lost and the focus is shifted solely to the artefact. In the context of higher education, it means the student's experience in the use of digital technology is lost (not reckoned with; ignored) or seen as totally abstract (intellectual) as if separated from his or her body. Students are, however, physical human beings and the use of technology in higher education should, in our view, always reckon with this. In brief: When there is not a sufficient and nuanced understanding of the richly intertwined and mutable dialectical relation between the human and the technological (as with disembodied and instrumentalist perspectives), the full transformative potential of technology use in higher education remains unexploited and may even become an obstacle for transformation.

Furthermore, the reductionist approach to technology as a form of social epistemology, leads to a profound confusion of the concepts of theory and praxis with regard to technology. Especially in pragmatism, theory and praxis (of technology) are often formulated as opposites. With the use of technology in higher education such a distinction between theory and practice is problematic, as the theory and the praxis of technology are intertwined in an idiosyncratic way that differentiates the field from the natural sciences and from socio-pragmatic approaches. Furthermore, a particularist account of technology (focusing on only a particular artefact) is not sufficient to describe the relationship between the individual and the digital technology artefact on a broader scale. The problem is that digital technology artefacts do not provide the whole picture of the phenomenon of technology, because of the phenomenon's intensified 'continual beginning' and its potential to become 'hidden' (Du Toit 2018:20-25). ${ }^{2}$ Attempts to understand technology through micro-studies (e.g. single applications) and a focus on the artefactual (e.g. smartphone) are only sufficient for investigating the 'phenomenon' of technology to a limited degree. It neglects the interplay between theory and praxis, between the technical and the phenomenal, and between the individual and the artefact. We suggest a phenomenological alternative to overcome the shortcomings of social constructivist and pragmatist approaches towards technology.

One problem with disembodied, reductionist and objectivist rationalist approaches towards digital technology is that such approaches inherently presume that individual experience of this contemporary form of technology is 'numbed' - the lived experience of the individual is disregarded, the phenomenon becomes 'cold' and 'alienating'. It is assumed that, through such systematised thinking on

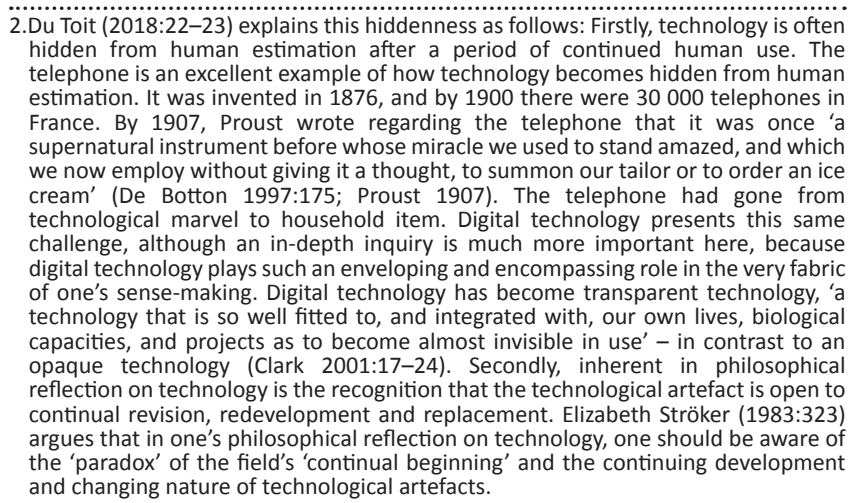

Du Toit (2018:22-23) explains this hiddenness as follows: Firstly, technology is often hidden from human estimation after a period of continued human use. The telephone is an excellent example of how technology becomes hidden from human estimation. It was invented in 1876, and by 1900 there were 30000 telephones in France. By 1907, Proust wrote regarding the telephone that it was once 'a supernatural instrument before whose miracle we used to stand amazed, and which we now employ without giving it a thought, to summon our tailor or to order an ice cream (De Botton 1997:175; Proust 1907). The telephone had gone from

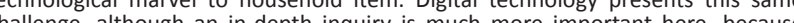
challenge, although an in-depth inquiry is much more important here, because of

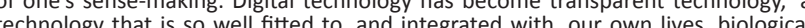

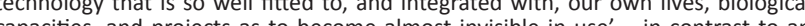
(Clark 2001:17-24). Secondly, inherent in conilosophical reflection on technology is the recognition that the technological artefact is open to covision, redevelopment and replacement. Elizabeth Ströker (1983:323) rgues that in one's philosophical reflection on technology, one should be aware of and changing nature of technological artefacts. 
digital technology, the individual is detached from himself or herself and others via digital technology. How then should one trace such a nebulous 'object' as technology? Because technology is increasingly used in higher education, this question becomes highly pertinent in and for this context. To answer this question, we suggest an approach to technology through embodied phenomenology. We reckon that such an approach allows one to describe the individual's experience of technology in an appropriately embodied manner; one in which the richly intertwined and mutable dialectical relation between the human and the technological comes to the fore. Merleau-Ponty's central phenomenological project (1962:xviii) allows a starting point for such an approach, because he argues that one should 'not overlook the phenomenon of the world and one's being present in it through our bodies'. Other approaches to technology do exactly this, overlooking the central phenomenon under investigation, and it is here where the correction should be made. Therefore, in the next section, we will explicate the embodied phenomenology of Merleau-Ponty and appropriate it with regard to digital technology. In the last section, we will return to the implications of an embodied understanding of digital technology for higher education and its transformation.

\section{An embodied understanding of technology: Merleau-Ponty's embodied phenomenology}

Merleau-Ponty's embodied phenomenology presents an alternative to disembodied and instrumentalist perspectives regarding the use of digital technology in higher education. Phenomenology in general, but particularly phenomenology in Merleau-Ponty's account (1962:viii) is a 'manner or style of thinking' that directs philosophical analysis to a 'direct and primitive contact' and description of the world. This stands in contrast to inadequate methodological approaches found in prominent contemporary Philosophy of Technology methodological approaches, and which are also found in posthumanism and in postphenomenology (which remains disembodied and instrumentalist). Instead of investigating technology qua technology from the side of artefacts (in a postulated body-artefact dichotomy), one's body is, for Merleau-Ponty, the starting point as the dynamic though constant framework to think from. In other words, MerleauPonty's unique development of phenomenology into an 'embodied phenomenology' presents a starting point for a deeper and more deliberate (holistic) inquiry into the phenomenon of digital technology.

To understand Merleau-Ponty's embodied phenomenology (1962) it is essential to highlight four principal themes with which he engages in his work: (1) Perception is the individual's entire bodily inhabiting of its environment; (2) perception is essentially perspectival and finite from the body (p. 81); (3) through perception the individual is absorbed within and directed towards objects within the world and 'forgets' the essence of consciousness in perception (p. 67; 1968:213) and (4) this sensual perceptual experience of the world extends to a perspectival structure of all human experience and understanding (Merleau-Ponty 1968; Carman 2008:1-3). These themes are reflected throughout Merleau-Ponty's phenomenological thought on embodiment and perception - to see the world (and technology) anew. Merleau-Ponty argues for the importance of an 'ante-predicative knowledge' the individual has of his or her body (Baldwin 2003:79), a re-engagement with one's 'bodily commerce with the world' (Taylor 2004:46), that the individual engages with the world through his or her bodily existence as an 'always "already there" before reflection begins' in the world. It is through phenomenological description that one '[re-achieves] a direct and primitive contact with the world' (Merleau-Ponty 1962:vii, 235) and one's body is central in this process. Bodily mediation entails the direct, lived experience of the world rather than through the application of strictures of theoretical constructs superimposed over one's experience of the world (MerleauPonty 1962:190).

For Merleau-Ponty, the 'body-subject' remains true to lived, bodily experience - it is grounded in contingent and temporal corporeal experience. Therefore, it is necessary for a re-conceptualisation of the body as it is in relation to the phenomenon of digital technology. The facticity of embodiment of the body-subject opens up space for a truly new understanding of all our experiences - also for digital technology in higher education. It requires a re-conceptualisation of the relation between the embodied individual and the digital technology artefact, wherein the embodied nature of the individual is a constant thread. This is especially relevant with regard to digital technology, because with older technology artefacts the immersion of the individual 'into technology' was not that rigorous. Digital technology has the effect that it immerses the individual in a unique and an unprecedented manner-one's perceptual and experiential horizons are broadened or narrowed through a symphony of digital technology devices such as smartphones, tablets and basically any other Internet-connected device working in unison. However, such an immersion is a bodily immersion par excellence (for the body is the foundation from where the phenomenon of digital technology is encountered) which necessitates an embodied approach to the understanding of digital technology. Without recognition of the bodily immersion of the individual through digital technology, some crucial emergent characteristics of the phenomenon of digital technology will not be accounted for. Such an account of the phenomenon of digital technology would remain fragmentary, limited and reductionist which is also the potential mistake to be made in understanding and using of digital technology in higher education. This will, in turn, undermine the potential power of the use of digital technology in transformation of higher education. Therefore, it is necessary to describe the phenomenon of digital technology from the basis of radical embodiment to reflect the unique nature of the immersion and intertwining of the embodied individual and the digital technology artefact. 
To return to Merleau-Ponty (1962) on this point, the body is the manner (or permanence) through which perception is possible - the permanence of the body is 'the ground for the relative permanence of disappearing objects' (p. 105). An important aspect of the centrality of the body in perception is the assumed facticity of body (in comparison to the posthuman conception of the body as infinitely malleable and changing). However, the body per the body-subject is not a simplistic concept. One problem with the description of digital technology from the basis of the body is the 'multiplication' of bodies that is suggested in the literature on digital technologies (such as 'virtual bodies' vs. the 'physiological body') and by the recourse to empirical accounts of technology (in particular postphenomenology). These approaches miss the foundational character of embodiment, the inherent facticity of the body as basis for perception, and the relevance of the body for a description of the phenomenon of digital technology. Even posthuman accounts of the phenomenon of digital technology start from the basis of questioning the relevance of the body as facticity in accounts of digital technology. Instead of a multiplication of bodies or taking empiricism as recourse, it is necessary for a re-conceptualisation of the body as it is in relation to the phenomenon of digital technology (again, in contrast to posthuman conceptualisations).

One needs to move beyond inadequate conceptualisations of the virtual body or a multiplication of bodies by asking what the nature of the body is. Merleau-Ponty conceptualises the body as the unitary basis of the individual's lived experience. He argues that a philosopher's idiom is always in one's nonprivate bodily being, but Merleau-Ponty's work opens up a space for considerations of other forms of being-in-the-body than his or her own body. He argues that there is no favoured style or modality of being just as there is no quantifiable measure of a minimum needed for bodily experience - all experience is 'full' experience, even if impoverished, incomplete or merely other. There exists in embodiment always the acknowledgement that our particular embodied situatedness could just as easily be another embodiedness, another situatedness. There is a transcendence, an intentionality and a unity of the body. However, the transcendence could be complete or ambiguous, the intentionality inhibited or unsure, and the unity discontinuous or staggered. Although there are many forms of body or ways of being-in-a-body, there is always the body as foundationally constitutive for perception and experience. The transcendence, intentionality and unity of body thus have the possibility of expansion, change and modulation in and through its experience of certain phenomena of which the phenomenon of digital technology has a unique power because of its potential immersion of the individual.

From the basis of the body-subject, Merleau-Ponty (1968: 248-51) postulates the flesh as an ontological notion of being itself. The flesh can capture the presence of things, because it is an elemental being, moving to adjust itself to the axes of the visible, for 'he who sees cannot possess the visible unless he is possessed by it, unless he is of it ...' (Merleau-Ponty 1968:134-135, 139). However, while we are of the world, we are paradoxically not the world (Merleau-Ponty 1968:127). ${ }^{3}$ The flesh presents a conceptual development of embodiment that has prominent implications for a description of the phenomenon of digital technology. The concept of the flesh finally shows that the world is not theoretically delimitable which means that the phenomenon of digital technology can never be separated from the world or our experience of the world. The non-delimitable nature of the world and the phenomenon of digital technology will form a central point of a foundational, encompassing and multimodal account of the phenomenon of digital technology. Importantly, the flesh is, in itself, not merely an extension of embodiment. MerleauPonty's concept of flesh presents an alternative to the traditional philosophical dualistic thinking on the separateness of body and world, self and other, subject and object, looking and being looked at, touching and being touched. ${ }^{4}$ It is the unitary concept of Merleau-Ponty's thought that leads to a unitary description of the phenomenon of digital technology.

Through the flesh, the phenomenon of digital technology encroaches upon one, and one's embodiment encroaches on the digital technology artefact. The body remains the stable yet dynamic foundation of this encroachment; one need not postulate posthuman changes in embodiment. Rather, there is encroachment upon one by the phenomenon of digital technology and vice versa in one's full humanity. In this originating encounter, this passage from the self unto the world is the space wherein the reciprocal intertwining of the relation between the human and digital technology occurs. It is this space that necessitates the concept of the 'Embodied Screen'. Both the individual and the artefact 'become' through the intertwining in lived experience, through perception based on perceptual faith. It is in this space where the transcendent rays of digital technology cross over into the body-subject. Merleau-Ponty (1968:65) describes this in a non-technological context as "What I find in "myself" is always the reference to this originating presence and to retire into oneself is identical to leaving oneself'. This seeming contradiction of 'retiring into and leaving oneself' is described by Merleau-Ponty as a chiasm, and this 'crossing over' (from oneself to the world and back) functions in a unique and overwhelming manner in the 'Embodied Screen' (when it comes to experiencing the phenomenon of digital technology). This chiasm (a 'there is' that is also an 'I am') creates meaning and cohesion, because I am the origin of a world in which I am already implicated. This does not imply idealism, but rather an opening up through the body to something else.

3.Just as there is encroachment between the two poles of these "dualisms', so the world encroaches upon us and alters us.

4.In this study, such reversibility occurs specifically between the human and digital technology. Such dualisms are challenged through Merleau-Ponty's suggestion of inseparable associon inseparable association between such elements, their en separateness - the chiasm and the intertwining. Reversibility and the chiasm form intrinsic concepts of Merleau-Ponty's conceptualisation of the flesh. In this regard and important for this study, the flesh is the foundational formulation of MerleauPonty's thought, arising from his tracing of the ontological implications of a phenomenology that could account for its own limitations in his final work (Merleau-Ponty 1968). 
It is from this point of meaning and cohesion that an embodied descriptive account of a 'disembodied' phenomenon such as the phenomenon of digital technology may be found. This also indicates why digital technology cannot be described as disembodied.

Perceptual faith, as the basis of perception, is the prereflective conviction that perception corresponds to the world as it actually is, while being mediated by the senses. It is the 'unjustifiable certitude of a sensible world' that underlies Merleau-Ponty's thought (1968:23-24) on perception and the world. In our engagement with the world this is unproblematic, but when rationally articulated its apparent paradoxical character leads to confusion. While the concept of perceptual faith is important in the interrogation of our lived experience, the Embodied Screen entails a continuing re-conceptualisation of this interrogation of our lived experience through specifically digital technology artefacts. In our lived experience of the phenomenon of digital technology, there is at once proximity (through questioning) and distance (what is not ourselves). Imaginative signification fills the spaces left by challenged perceptual faith. In the Embodied Screen this open-ended continuum and continual interplay (between the real and the imaginary) become of central importance, for, between the embodied facticity of the individual and the infinite possibilities that digital technology artefacts present, lies the lived experience of the phenomenon of digital technology. It is both perception and the imagination bound together by perceptual faith that are challenged by digital technology artefacts and which necessitates imaginative signification. The embodied nature of the individual is therefore a constant thread and it is this concept of the body (following Merleau-Ponty) that must be utilised in describing the relation between the human and digital technology artefacts, conceptually encapsulated in a neologism: The Embodied Screen.

The Embodied Screen is a nuanced and technical neologism which is argued to allow insight into the interaction of the embodied individual with the phenomenon of digital technology and into digital technology artefacts themselves, particularly in higher education. The Embodied Screen can be described as that access point that exists as modulation between a multitude of digital technology artefacts and the embodied individual through which there is a reciprocal engagement between both these two 'poles'. The screen is the hyper-modulation of flesh that allows passage between the embodied individual and digital technology artefacts in a unique manner that cannot but be described by means of embodied concepts because of the foundationally embodied though reversible character of this relationship. It specifically describes that unique contact point (a 'see-through' and 'double-sided' screen) between the embodied individual and digital technology artefacts. The Embodied Screen is thus the creative application and re-deployment of Merleau-Ponty's embodied phenomenology to the phenomenon of digital technology.
The Embodied Screen postulates unique access to the phenomenon of digital technology from the foundation of the individual's pre-theoretical, lived embodiment and through the particular modulation of the flesh by digital technology artefacts. When these foundational points are used as a starting point, a richly intertwined and mutable dialectic relationship is revealed between the embodied individual and digital technology artefacts. On the one pole of this dialectic relationship stands the embodied facticity of the individual, and on the other pole, the digital technology artefact - the phenomenon of digital technology is found in the 'between' of these two poles and only arises in this circuit between body and artefact. The Embodied Screen conceptually encapsulates the individual's body and the digital technology artefact as well as the unique emergent characteristics that arise from this relationship in the phenomenon of digital technology. These emergent characteristics (which may seem tangential) are crucial for explaining how the individual's embodied sense-making is challenged and altered in the individual's experience of the self, the other and the world in the phenomenon of digital technology.

The Embodied Screen is transparent; it is a porous 'membrane' where reciprocal interaction between the embodied individual, through his or her flesh as the totality of sense experience and the digital technology artefact takes place. This is a reversible, intertwined relationship - the individual touches and is touched in digital technology interactions. Such reversibility and modulation of the flesh challenge and change the embodied individual's sense-making through, amongst others, challenges to perceptual faith and increased imaginative signification.

\section{Conclusion}

\section{An embodied understanding of technology and transformation of higher education}

As explained above, an instrumentalist understanding of technology has been dominant in the broader field of Philosophy of Technology since the empirical turn as of the 1980s onwards. This disembodied approach to technology derives from and is typical of pragmatism and social constructivism. Within the higher education context, the enticement might be strong to follow this understanding of technology and thereby neglecting the embodied nature of technology. There are several problems with such a disembodied reductionist approach to technology, for instance: (1) the individual becomes detached from himor herself and others via digital technology; (2) digital technology becomes 'cold' and alienating; (3) the personhood and context of the student (user of technology) is ignored; (4) micro-studies on specific technology gets priority and not its broader effect and relationship with the individual; and (5) the individual's embodied sensemaking of the world and others is not reckoned with. We have called for an alternative, non-instrumentalist understanding of technology. 
Through the embodied phenomenology of Merleau-Ponty, an alternative approach to digital phenomenology was delineated. Such an approach can be encapsulated by the concept 'Embodied Screen' in which the reciprocal interaction between the embodied individual through his or her flesh as the totality of sense experience and the digital technology artefact is described. Such an embodied understanding of digital technology may, first of all, challenge the way digital technology is predominantly understood and eventually used in higher education. An embodied understanding of digital technology has some significant implications for transformation of higher education. The epistemic framework of technology use in higher education is hereby altered as the following examples illustrate.

Firstly, transformation in higher education includes notions of decolonisation in which it becomes imperative that (post)colonial subjects will be able to recognise themselves within higher education (Fanon 1967:191). This implies 'possibilities of finding alternative schemes of thought, and of thinking critically about who and what the human in becoming is in (post)colonial contexts' (Becker 2017:7). To neglect these questions about the becoming of humans, the personhood of people and the historical context of students are all (unintended) consequences of an instrumentalist understanding and use of technology. In contrast, an embodied understanding of technology keeps in mind the embodied interaction of students with technology - it is always an embodied understanding. The personhood of the student is reckoned with. His or her language, culture, perceptual faith and imagination are not sidestepped through the use of digital technology, but remain fundamentally part of such technology use.

Secondly, an instrumentalist understanding of technology may promote a use of digital technology as if it is a mere tool to be given to everybody to be equally accepted and effectively used. The social contexts and personal embodiedness of those given this technology to are ignored. In effect, it is similar to give a spade to a hungry person and a well-fed person and expect them to use the tool to the same effect - as if the differences between them are now erased with each having a spade. With digital technology, a 'digital divide' has occurred because of this attitude. This digital divide is 'constructed socio-economically rather than generationally, with users from privileged backgrounds tending to use the Internet more widely and effectively than their less privileged peers' (Flavin 2017:87). To transform higher education to 'redress past inequalities' (South Africa, Department of Education 1997:2) and to be not exclusive in terms of class (and others) therefore needs a more holistic and embodied understanding of digital technology.

Thirdly, an embodied understanding of digital technology challenges the transformation of higher education to not uncritically embrace the use of digital technology. Because digital technology challenges and alters the individual's experience of the self, the other and the world, it should be used with responsibility, sensitivity and expertise. It should be kept in mind, for example, that a certain ontology, epistemology and values are conveyed through the use of digital technology. The role of power (and politics) cannot be ignored. Digital technology sets the user in a 'certain mind-set' - that of the program developer, the device developer and the interface without face. With constant alteration of the self (identity), the world, imagination and perceptual faith that takes place by using digital technology, questions about power and control (especially in a consumer world) become pertinent.

The use of digital technology in higher education has a huge positive effect on various aspects of enhancing learning and teaching practices. This is not denied in this article, but rather confirmed. The ambiguity of the use of digital technology in higher education should not be ignored, however, but critically addressed. The way digital technology is used is often based on a certain understanding of it, for example an instrumentalist one. To transform higher education, a more bodily understanding of digital technology is needed. Therefore, we argued in this article that a more holistic and embodied understanding of technology can be developed through the embodied phenomenology of Merleau-Ponty - encapsulated in the concept the Embodied Screen.

In the absence of a sufficient and nuanced understanding of the richly intertwined and mutable dialectical relation between the human and the technological (as with disembodied and instrumentalist perspectives), the full transformative potential of technology use in higher education, remains unexploited and may even become an obstacle for transformation. Digital technology can (and already does) play a pivotal role in the transformation of higher education. Because transformation of higher education in the South African context entails social and concrete bodily transformation, a broader, more holistic and embodied understanding of digital technology is needed in higher education.

\section{Acknowledgements Competing interests}

The authors declare that they have no financial or personal relationships which may have inappropriately influenced them in writing this article.

\section{Authors' contributions}

J.d.T. and A.H.V. were the co-authors of this article. J.d.T. provided material from his $\mathrm{PhD}$ for the Merleau-Ponty sections, while A.H.V. provided the basis for the application in terms of higher education in South Africa in the Introduction and Conclusion.

\section{References}

Adams Becker, S., Cummins, M., Davis, A., Freeman, A., Hall Giesinger, C. \& Ananthanarayanan, V., 2017, NMC Horizon Report: 2017 Higher Education Edition, The New Media Consortium, Austin, TX.

Baldwin, T., 2003, Maurice Merleau-Ponty: Basic writings, Routledge, London. 
Becker, A., 2017, 'Rage, loss and other footpaths: Subjectification, decolonisation and transformation in higher education' Transformation in Higher Education 2(0), a23. transformation in higher education,

Carman, T., 2008, Merleau-Ponty, Routledge, London.

Clark, A. \& Chalmers, D., 1998, 'The extended mind', Analysis 58(1), 7-19. https://doi. org/10.1093/analys/58.1.7

Clark, A., 2001, 'Natural-born cyborgs?', in Cognitive technology: Instruments of mind $-4^{\text {th }}$ International Conference, CT 2001, Proceedings (vol. 2117), Springer Verlag, Berlin, Germany, August 6-9, 2001, pp. 17-24.

De Botton, A., 1997, How Proust can change your life, Picador, London.

Du Preez, P., Simmonds, S. \& Verhoef, A.H., 2016, 'Rethinking and researching transformation in higher education: A meta-study of South African trends' Transformation in Higher Education 1(1), a2. https://doi.org/10.4102/the.v1i1.2

Du Toit, J., 2018, 'Towards a Merleau-Pontian account of the phenomenon of digital technology: From disembodiment to the Embodied Screen', PhD thesis, NorthWest University.

Fanon, F., 1967, Black skin, white masks, Grove Press, New York.

Flavin, M., 2017, Disruptive technology. Enhanced learning. The use and misuse of digital technologies in higher education, MacMillan Publishers, London.

Georgina, D.A. \& Olson, M.R., 2008, 'Integration of technology in higher education: A review of faculty self-perceptions', Internet and Higher Education 11, 1-8. https:// doi:10.1016/j.heduc.2007.11.002

Kirkwood, A. \& Price, L., 2014, 'Technology-enhanced learning and teaching in higher education: What is 'enhanced' and how do we know? A critical literature review' Learning, Media and Technology 39(1), 6-36. https://doi.org/10.1080/17439884. Learning, Me

Merleau-Ponty, M., 1962, Phenomenology of perception, transl. C. Smith, Routledge \& Kegan Paul, London.

Merleau-Ponty, M., 1968, The visible and the invisible, ed. C. Lefort, transl. A. Lingis, Northwestern University Press, Evanston.
Proust, M., 1907, 'Impressions de route en automobile', Le Figaro: journal non politique, Nov, 53(3), pp. 11-19.

South Africa, Department of Education, 1997, Education White Paper 3: A programme for the transformation of higher education, Government Gazette, vol. 390, no. 18515, Government Printers, Pretoria.

South Africa, Department of Education, 2008, The report of the Ministerial Committee into Transformation in Higher education (MCTHE), Department of Education Pretoria.

Ströker, E., 1983, 'Philosophy of technology: Problems of a philosophical discipline', in P.T. Durbin \& F. Rapp (eds.), Boston studies in the philosophy of science; v. 80: Philosophy and Technology: Proceedings ... of a joint West German-North American conference on philosophy of technology, held at the Werner-Reimers Stiftung, Bad Homburg (near Frankfurt), West Germany, April 7-11, 1981, pp. 323-336, Reidel, Dordrecht.

Taylor, C., 2004, 'Merleau-Ponty and the epistemological picture', in T. Carmen \& M.B.N. Hansen (eds.), The Cambridge Companion to Merleau-Ponty, pp. 26-49, Cambridge University Press, Cambridge.

Underwood, J., 2009, The impact of digital technology: A review of the evidence of the impact of digital technologies on formal education, Becta, Coventry.

United States, Department of Education, 2017, Office of educational technology. Supplement to the national education technology plan: Reimagining the Role of
Technology in Higher education, Department of Education, Washington, DC, viewed 07 June 2018, from https://tech.ed.gov/files/2017/01/Higher-Ed-NETP.pdf

Waghid, Z. \& Waghid, F., 2016, 'Examining digital technology for (higher) education through action research and critical discourse analysis', South African Journal of Higher Education 30(1), 265-284. https://doi.org/10.20853/30-1-562

Wainer, J., Dwyer, T., Dutra, R.S., CoMerleau-Ponty, A., 1968, Magalhães, V.B., Ferreira, L.R., Pimenta, V.A. \& Claudio, K., 2008, 'Too much computer and Internet use is bad for your grades, especially if you are young and poor: Results from the 2001 Brazilian SAEB', Computers and Education 51, 1417-1429. https://doi. org/10.1016/j.compedu.2007.12.007

Wankle, C., 2011, Teaching arts and science with new social media, vol. 3, Emerald Group Publishing Limited, New York. 